\title{
EL DERECHO DE INVESTIGAR Y EL DEBER DE DIFUNDIR LO INVESTIGADO.
}

POZO-CABRERA ENRIQUE *
Recibido: 28/12/2015

Aceptado: 08/01/2016

Existen expresiones en el Derecho que nos conducen a varias definiciones; de entre ellas, pueblo, libertad, soberanía y por supuesto, Derechos Humanos; estas definiciones pueden ser amplias o restringidas; lo que nos conduce a pensar si estas ambigüedades debilitan los conceptos haciendo complicado su concreción y fundamentalmente su aplicación.

Mientras más se discuta los conceptos de igualdad y libertad, más se ha de desarrollar el concepto de dignidad; del hombre como un fin en sí mismo. Lo dicho, es el imperativo categórico de Kant que de una manera amplia señala: "obra de tal modo que use a la humanidad, tato en tu persona como en la persona de cualquier otro, siempre como un fin al mismo tiempo, y nunca solamente como un medio" (Gil Olivera, 2003).

El derecho a la dignidad de la persona consiste en la autonomía de la voluntad, en la autodeterminación y en la libertad de planificar y proyectar su futuro; en consecuencia, todo ser humano tiene derecho a investigar; todos tienen capacidad para investigar.

Pero, existen personas que se han capacitado para investigar; estas personas tienen la obligación de investigar y tienen el deber de difundir lo investigado. La Asamblea General de las Naciones Unidas, en la Resolución 2200, de 16 de Diciembre de 1966 reconoció en el Art. 15 este Derecho:

“1. Los Estados Partes en el presente Pacto reconocen el derecho de toda persona a:

a) Participar en la vida cultural;

b) Gozar de los beneficios del progreso científico y de sus aplicaciones;

c) Beneficiarse de la protección de los intereses morales y materiales que le correspondan por razón

de las producciones científicas, literarias o artísticas de que sea autora.

2. Entre las medidas que los Estados Partes en el presente Pacto deberán adoptar para asegurar el pleno ejercicio de este derecho, figurarán las necesarias para la conservación, el desarrollo y la difusión de la ciencia y de la cultura.

3.- Los Estados Partes en el presente Pacto se comprometen a respetar la indispensable libertad para la investigación científica y para la actividad creadora. 4.- Los Estados Partes en el presente Pacto reconocen los beneficios que derivan del fomento y desarrollo de la cooperación y de las relaciones internacionales en cuestiones científicas y culturales" (Naciones Unidas Derechos Humanos , 1966).

La Constitución ecuatoriana, como norma teleológica ${ }^{1}$, en el Art. 66.6 señala: "El derecho de opinar y expresar su pensamiento libremente y en todas sus formas y manifestaciones" (Constitución , 2008, p. 10)

Encontrar una definición de pensamiento; es realmente complicado; diremos que es universal en todos los seres humanos y parafraseando a Descartes diría que, entiendo por pensamiento todo lo que sucede en nosotros de tal modo que lo percibimos inmediatamente por nosotros mismos; en consecuencia, no es solo entender, querer, imaginar, sino también sentir que es lo mismo que pensar.

"Lonergan parte del análisis del acto del conocimiento como conjunto de operaciones trascendentales del ser humano, mediante las cuales éste se expresa, se desarrolla, se abre al mundo. El conocimiento es un acto intencional" (Groppa, 2015, p. 24).

Por lo tanto, nadie puede limitar el derecho al pensamiento; ni la más atroz de las dictaduras lo limitaría; el pensar termina con la muerte; pero, cuando ese pensamiento ha de expresarse ya tiene limitaciones; el honor de los demás, la buena fama de los otros y más.

El pensamiento en libertad generado puede expresarse sin importar forma; pero, si con los límites que determina el derecho y dentro de estas manifestaciones de expresión, está la investigación.

* Rector Titular Universidad Católica de Cuenca. Ecuador

${ }^{1}$ Sobre esta tipología de norma se puede ampliar en su análisis en Antonio E. Pérez Luño, en "LOS DERECHOS FUNDAMENTALES". "Este tipo de normas hacen relación a la función de los fines perseguidos por los distintos derechos" 
Desde el punto de vista de las normas materiales ${ }^{2}$, el derecho a la investigación y su difusión se encuentran en los Arts. 22, 385, 386, 387 y desde la perspectiva de las normas formales ${ }^{3}$ el derecho de investigación y difusión que se encuentra en el Art. 388 de la Carta Constitucional.

El Derecho a la investigación y su difusión, es un derecho subjetivo público ${ }^{4}$; pero, al mismo tiempo es un deber social. El titular del derecho es la persona; todos los que somos parte de la sociedad; pero, el que investiga tiene el deber de informar en procura de la igualdad de la sociedad.

\section{REFERENCIAS BIBLIOGRÁFICAS}

Constitución . (2008). Constitución del Ecuador . Obtenido de http://www.produccion.gob.ec/wpcontent/uploads/downloads/2012/07/Normas_Constitucionales.pdf

Gil Olivera, N. (2003). DERECHO Y DIGNIDAD. Ensayos de Filosofía política. BOGOTA: GUSTAVO IBAÑEZ.

GIL OLIVERA, N. (2003). DERECHO Y DIGNIDAD. Ensayos de Filosofía política. BOGOTA: GUSTAVO IBAÑEZ.

Groppa, O. (2015). XIII. Aportes a una epistemología de base ética. Explicación de fundamentos para un trabajo interdisciplinar. Obtenido de http://www.uca.edu.ar/uca/common/grupo32/files/13-aportes-epistem-2002.pdf

Naciones Unidas Derechos Humanos . (1966). Pacto Internacional de Derechos Económicos, Sociales y Culturales. Obtenido de http://www.ohchr.org/SP/Professionallnterest/Pages/CESCR.aspx

Enrique Pozo (2016). EPISTEMIOLOGÍA Y ACCESO ABIERTO EN LA INFORMACIÓN CIENTÍFICA E INVESTIGACIÓN. CUENCA

\footnotetext{
${ }^{2}$ Ibidem. Estas normas hacen relación al objeto, contenido o modalidades de ejercicio de los mismos.

${ }^{3}$ Ibidem. Estas normas hacen relación a los instrumentos y garantías dirigidos a su tutela.

${ }^{4}$ En expresión Luis María Díez-Picazo, el derecho subjetivo público es aquel que tienen los particulares que están vinculados al campos del Derecho Público como es el caso de la Constitución y la Ley Orgánica de Educación Superior.
} 